\title{
CARACTERIZAÇÃO DE SOLDAS COM UNDERMATCHING EM CHAPAS DE AÇO HARDOX 450*
}

\author{
Pablo Reis Dias \\ Lívia Maria Fernandes de Sousa \\ Francisco de Assis Souza Neto \\ Márcio Corrêa de Carvalho \\ Eduardo de Magalhães Braga ${ }^{7}$
}

\section{Resumo}

A necessidade da aplicação dos aços de alta dureza é recorrente nas indústrias de mineração, visto que esses equipamentos são submetidos continuamente a esforços mecânicos. Por isso o objetivo deste trabalho é caracterizar uma amostra de aço Hardox 450 HB soldada pela técnica undermatching com a finalidade de se avaliar a sua soldabilidade, dureza e microestrutura, qualificando a sua predisposição para o uso fabril. Realizou-se o ensaio de composição química, o ensaio metalográfico e o de microdureza afim de se comparar com os dados de fabricantes deste aço e avaliando com os parâmetros de soldagem aplicados a sua susceptibilidade à propagação de trincas. Observou-se que a microestrutura revelada é a martensita com conformação de grãos mais refinados entre o metal de base e o metal de adição. Através da análise química percebeu-se que de acordo com o valor do carbono equivalente, este aço possui média soldabilidade.

Palavras-chave: Soldabilidade; Hardox 450 HB; Undermatching; Trincas;

\section{CHARACTERIZATION OF UNDERMATCHING WELDING ON HARDOX 450 STEEL SHEETS}

\section{Abstract}

The need for the application of high hardness steels is recurrent in the mining industries, since these equipments are continuously subjected to mechanical stresses. Therefore, the objective of this work is to characterize a sample of Hardox $450 \mathrm{HB}$ steel welded by the undermatching technique in order to evaluate its weldability, hardness and microstructure, qualifying its predisposition for industrial use. The test of chemical composition, the metallographic and the microhardness was performed in order to compare with the data of the manufacturers of this steel and evaluated with the parameters of welding applied its susceptibility to the propagation of cracks. It has been observed that the disclosed microstructure is martensite with finer grained conformation between the base metal and the addition metal.Through the chemical analysis it was noticed that according to the value of carbon equivalent, this steel has medium weldability..

Keywords: Weldability;Hardox 450 HB; Undermatching; Cracks;

1 Graduando em Engenharia de Materiais, Estudante, Universidade Federal do Sul e Sudeste do Pará, Marabá, Pará, Brasil.

2 Graduando em Engenharia de Materiais, Estudante, Universidade Federal do Sul e Sudeste do Pará, Marabá, Pará, Brasil.

3 Engenharia Mecânica, Mestre, Engenheiro de Manutenção, Ferrosos Norte, Vale S/A, Parauapebas, Pará, Brasil.

4 Engenharia Química, Doutor, Professor, Faculdade de Engenharia de Materiais, Universidade Federal do Sul e Sudeste do Pará, Marabá, Pará, Brasil.

5 Engenharia Mecânica, Doutor, Professor, Faculdade de Engenharia Mecânica, Universidade Federal do Pará, Marabá, Pará, Brasil.. 


\section{INTRODUÇÃO}

$\mathrm{Na}$ mineração, os equipamentos utilizados para extração de minério, como britadores, revestimento de calhas e transportadores são submetidos a grandes esforços continuamente, logo, necessitam de alta resistência mecânica e a abrasão para evitar o desgaste dos mesmos. Para atender esta demanda, chapas de aço de baixa liga temperados e revenidos com alta resistência mecânica e dureza foram desenvolvidas em diversas usinas siderúrgicas afim de suprir essas necessidades, como é o caso do aço Hardox 450, classificado pela sua dureza na escala Brinell 450HB.

O aço Hardox 450 é caracterizado por ter elevada resistência mecânica e alta dureza, sendo aplicado em áreas onde se faz necessário grandes esforços, não ocasionando a deformação da peça. É utilizado na fabricação de caçambas, martelos, revestimentos e qualquer que seja a aplicação que requer esta alta resistência ao impacto que o aço pode proporcionar (COSTA, 2014). Este aço é produzido por laminação a quente e processado por um tratamento térmico de têmpera, o que Ihe confere soldabilidade e dureza, afinal, foi projetado para possuir resistência ao desgaste e à trincas.

Apesar do Hardox 450 apresentar uma alta dureza, mais difícil é de soldálo, pois o aumento da resistência da dureza na zona termicamente afetada ou no metal de solda pode facilitar a propagação de trincas transversais, longitudinais, trincas na margem e no cordão da zona afetada pelo calor, dependendo das condições de soldagem imposta e do aporte térmico. A perda de tenacidade na ZTA ou na zona fundida são ocasionadas pela variação do aporte térmico, já a velocidade de resfriamento é o fator que influencia de forma significativa na microestrutura da solda e na região fundida, por isso é muito importante o controle dos parâmetros de soldagem, para que não ocorra a fragilização da peça por alto endurecimento e mudança da microestrutura do metal da peça.

Dentre os métodos desenvolvidos e já utilizados para a caracterização do aço Hardox 450HB, encontra-se nos relatos de Viegas (2016), que realizou ensaios no espectrômetro de emissão óptica para a análise da composição química do metal de base e do metal de adição, em que ao comparar com os dados de fabricação deste aço, os resultados se encontraram dentro das especificações de fábrica. Em relação ao ensaio de microdureza, que procedeu-se em duas amostras diferentes, 
uma com metal de adição e outra sem o metal de adição, investigou-se que o teste realizado na peça com o metal de adição determinou uma dureza menor do que na peça sem o revestimento do metal de soldagem

Além deste, Costa (2014) utilizou técnicas de metalografia (macrografia e micrografia) de acordo com a normas estabelecidas, em que para o ensaio de macrografia, atacou com o reagente nital $5 \%$ e para o ensaio de micrografia, a superfície do Hardox $450 \mathrm{HB}$ foi atacada com nital $2 \%$, ambos pela técnica de imersão. Nos resultados, identificaram que fatores como velocidade da soldagem podem ter influenciado na falta de fusão entre o metal de solda e o metal de base e que a microestrutura do metal de base se tratava de martensita revenida, favorecendo maior resistência e tenacidade ao aço.

Dessa forma, este trabalho tem a finalidade de realizar uma análise metalográfica, química e de microdureza de uma amostra do aço Hardox 450 HB, para comparar com os dados teóricos e de fabricação do mesmo, como a eficiência da solda para este tipo de aço.

\section{MATERIAIS E MÉTODOS}

\subsection{MATERIAL ANALISADO}

O material utilizado para análise neste trabalho é uma amostra do aço Hardox da classe $450 \mathrm{HB}$, o qual foi soldado pelo processo de arame tubular multipasse (FCAW). Vale ressaltar que este material é laminado a quente e tratado termicamente por têmpera e revenido, visando alcançar as propriedades mecânicas de alta dureza e tenacidade necessárias para as suas aplicações.

\subsection{PARÂMETROS DE SOLDAGEM}

De acordo com Souza Neto et al. (2015), a soldagem realizada neste corpo de prova foi o processo de soldagem a arco elétrico com arame tubular não metálico (FCAW), o qual apresentava um diâmetro de 1,2 milímetros, utilizando o consumível AWS A5.29 E81T1-Ni1CJH5, bocal da tocha número 12, stickout 12 a 15 
milímetros, polaridade inversa e gás de proteção $100 \% \mathrm{CO}_{2}$, com vazão de $18 \mathrm{l} / \mathrm{min}$. Para a soldagem, foi preparado uma junta de topo com chanfro em "V" e ângulo de abertura de $60^{\circ}$, na posição horizontal (2G) com altura da face e abertura de raiz equivalente a 2,0 milímetros. Com o auxílio da esmerilhadeira e lixadeira, realizou-se a goivagem por trás da amostra, afim de se obter a contrasolda do passe de raiz.

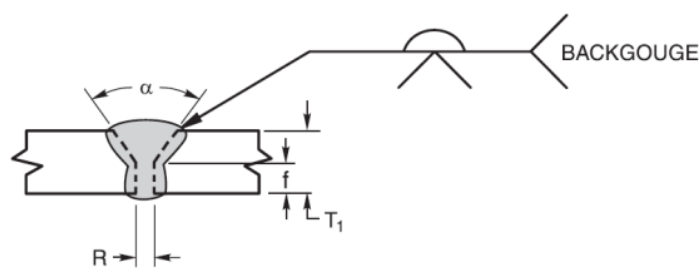

\begin{tabular}{cc}
\hline \hline Espessura da chapa (T1) & $25,4 \mathrm{~mm}$ \\
Abertura de raiz (R) & $2 \mathrm{~mm}$ \\
Altura da face da raiz (f) & $2 \mathrm{~mm}$ \\
Ângulo do chanfro (a) & $60^{\circ}$ \\
\hline
\end{tabular}

Figura 1: Geometria da junta do corpo de prova.

O aporte térmico foi calculado de acordo com a Equação 1, considerando a constante $k$ para eficiência térmica do processo de soldagem $(K=0,8)$.

$$
E(\mathrm{~kJ} / \mathrm{mm})=\frac{(\text { volts } \times \text { amps } \times 60)}{\text { vel } \cdot \text { soldagem }(\mathrm{mm} / \mathrm{min}) \times 1000} \times \mathrm{K}
$$

A partir da quantidade de carbono equivalente conhecida de 0,59 e a quantidade decarbono do metal de base de $0,2 \%$, a American Welding Society (AWS) afirma que se trata de um metal de base em que necessita de precauções durante seu processo, fazendo-se necessário utilizar o método de controle de hidrogênio $\left(\mathrm{P}_{\mathrm{cm}}\right)$ para determinar o pré-aquecimento. Dessa forma, os parâmetros de soldagem utilizados abrangeram o método de controle de hidrogênio, com a finalidade de se determinar o pré-aquecimento e assim proceder com a soldagem utilizando um menor valor de aporte térmico, preservando as propriedades da zona termicamente afetada e da zona fundida para possibilitar uma melhor soldabilidade da amostra.

Sabendo-se que o valor do parâmetro de composição $\left(\mathrm{P}_{\mathrm{cm}}\right)$ é igual $0,32 \mathrm{e}$ Index de Susceptibilidade igual a 4,54, o pré-aquecimento mínimo será de $140^{\circ} \mathrm{C}$, logo, através da tabela 1, pode-se observar os valores de parâmetros de soldagem utilizados nesta amostra, os quais foram descobertos devido o valor do carbono equivalente e do método de controle de hidrogênio apresentados. 


\begin{tabular}{cccc}
\hline $\begin{array}{c}\text { Corrente } \\
(\mathbf{A})\end{array}$ & $\begin{array}{c}\text { Tensão } \\
(\mathrm{V})\end{array}$ & $\begin{array}{c}\text { Velocidade do arame } \\
(\mathbf{m} / \mathbf{m i n})\end{array}$ & $\begin{array}{c}\text { Velocidade de soldagem } \\
(\mathbf{m m} / \mathbf{m i n})\end{array}$ \\
\hline $\begin{array}{c}262,2 \pm \\
10,5\end{array}$ & $25,8 \pm 0,7$ & 6,5 & $277,1 \pm 46,1$ \\
\hline \multicolumn{5}{c}{ Temperatura de pré- } \\
\hline \hline \\
\hline Energia de \\
soldagem & aquecimento $\left({ }^{\circ} \mathbf{C}\right)$ & $\begin{array}{c}\text { Temperatura de } \\
\text { interpasse }\left({ }^{\circ} \mathrm{C}\right)\end{array}$ \\
\hline \hline $1,2 \pm 0,2$ & 180 & $170 \pm 20$ \\
\hline
\end{tabular}

Tabela 1: Parâmetros de soldagem utilizados na confecção do corpo de prova.

\subsection{PREPARAÇÃO DO CORPO DE PROVA}

Inicialmente, cortou-se o aço Hardox $450 \mathrm{HB}$ com o auxílio de um disco de policorte. Em seguida, o corpo de prova foi submetido às técnicas de preparação de amostras metalográficas padrão, e depois realizar o ataque químico, realizado com nital $2 \%$ pelo método de imersão.

\subsection{ANÁLISE QUÍMICA}

O ensaio de composição química foi efetuado com o espectrômetro de emissão óptica OXFORD modelo FOUNDRY MASTER no metal de solda e no metal de base. Este procedimento acusou a porcentagem de cada elemento que compõe 0 corpo de prova, permitindo encontrar o carbono equivalente a partir de uma equação, indicando se o aço estará sujeito à trincas a frio, determinando a qualidade da solda.

\subsection{METALOGRAFIA}

Revelada a microestrutura da peça através do ataque químico, foi realizada a micrografia e macrografia da amostra, possibilitando identificar o metal de base, o metal de adição e a ZTA do corpo de prova, macrograficamente. 
Posteriormente, a partir de um microscópio eletrônico, procedeu-se o ensaio micrográfico, possibilitando distinguir e identificar as fases microestruturais do metal de solda, da ZTA e do metal de base, assim, verificou-se as propriedades mecânicas associadas as microestruturas apresentadas.

\subsection{MICRODUREZA}

O teste de microdureza foi realizado em um microdurômetro MITUTOYO ao longo de quatro linhas transversais diferentes: topo, meio 1 , meio 2 e base. 0 ensaio começou a uma distância de $20 \mathrm{~mm}$, partindo da esquerda para direita, mantendo um intervalo de $1 \mathrm{~mm}$ de distância entre um ponto e outro. Cada linha de teste andou entre 30 e $50 \mathrm{~mm}$, todas passando pelo metal de base e metal de solda até atingir o outro lado do metal de base.

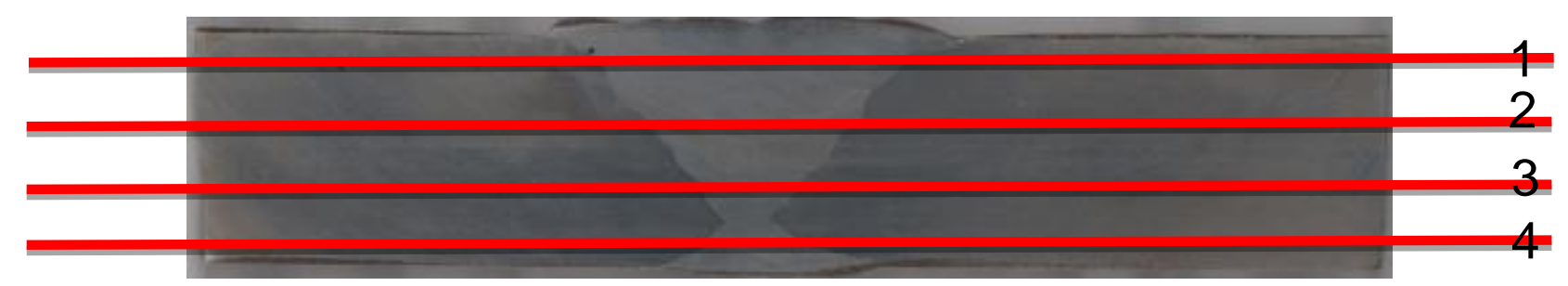

Figura 2: Figura esquemática das microdurezas.

\section{RESULTADOS E DISCUSSÃO}

\subsection{ANÁLISE QUÍMICA}

As tabelas 2 e 3 apresentam os resultados da média das 6 queimas da composição química do metal de adição e das 10 queimas do metal de base da amostra de aço Hardox 450 HB.

\begin{tabular}{ccccccccccc}
\hline & $\mathbf{C}$ & $\mathbf{S i}$ & $\mathbf{M n}$ & $\mathbf{P}$ & $\mathbf{S}$ & $\mathbf{C r}$ & $\mathbf{N i}$ & $\mathbf{M o}$ & $\mathbf{V}$ & $\mathbf{C u}$ \\
\hline $\mathbf{C}$ & 0,056 & 0,25 & 1,3 & 0,010 & 0,017 & 0,025 & 0,97 & 0,014 & 0,006 & 0,037 \\
$\mathbf{P}$ & 2 & 9 & 2 & 5 & 1 & 7 & 5 & 8 & 7 & 8 \\
& & & & & & & & & & \\
\hline
\end{tabular}

Tabela 2: Composição química do metal de adição.

\begin{tabular}{cccccccccccc}
\hline$(\%)$ & $\mathbf{C}$ & $\mathbf{S i}$ & $\mathbf{M n}$ & $\mathbf{P}$ & $\mathbf{S}$ & $\mathbf{C r}$ & $\mathbf{N i}$ & Mo & B & V & Cu \\
\hline C.P & 0,228 & 0,214 & 1,57 & 0,017 & 0,002 & 0,512 & 0,074 & 0,028 & 0,005 & 0,011 & 0,183
\end{tabular}




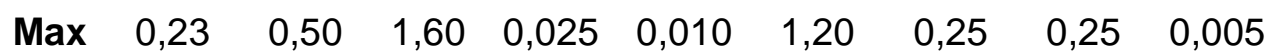

Tabela 3: Composição química do metal de base Hardox 450 HB.

De acordo com a tabela 2 da média da composição química do metal de adição, a presença de Manganês e Níquel, apesar de Níquel não se encontrar em grandes quantidades, favorece a formação de ferrita poligonal, que se organiza em formas aleatórias, responsável por proporcionar alta resistência e tenacidade.

Levando em consideração que na tabela 3 de composição química do metal de base apresentam os valores em porcentagem dos elementos do corpo de prova e da porcentagem máxima dos elementos do aço Hardox 450, especificados pelo fabricante SSAB, pode-se afirmar que os elementos estão de acordo com os parâmetros definidos do aço estudado. De acordo com relatos de Jun et al. (2006), elementos de liga como $\mathrm{Mn}, \mathrm{Ni}, \mathrm{Mo}, \mathrm{Cr}$ e B são constantemente incorporados aos aços estruturais afim de melhorar a resistência e a tenacidade através da alteração da microestrutura. Também pode-se afirmar que 0 aço apresenta boa temperabilidade, visto que a quantidade presente do elemento Boro proporciona isto.

Através da equação 2 , foi possível calcular o carbono equivalente do metal de base, resultando em um valor igual a 0,6175 , o que indica que o aço Hardox 450 HB possui média soldabilidade, ou seja, existe maior possibilidade de propagação de trinca frio, logo, Souza Neto et al. (2015) afirma que se deve ter um cuidado maior na definição dos parâmetros de soldagem e que é necessário o método de controle de hidrogênio $\left(\mathrm{P}_{\mathrm{cm}}\right)$ para determinar o pré-aquecimento.

$$
C_{e q}=\% C+\frac{\% M n}{6}+\frac{\% M o+\% C r+\% V}{5}+\frac{\% \boldsymbol{N}+\% \boldsymbol{C u}}{15}
$$

\subsection{MACROGRAFIA}

A figura 3 representa a macrografia da amostra do aço Hardox $450 \mathrm{HB}$ soldada com o arame tubular AWS A5.29 E81T1-Ni1CJH5.

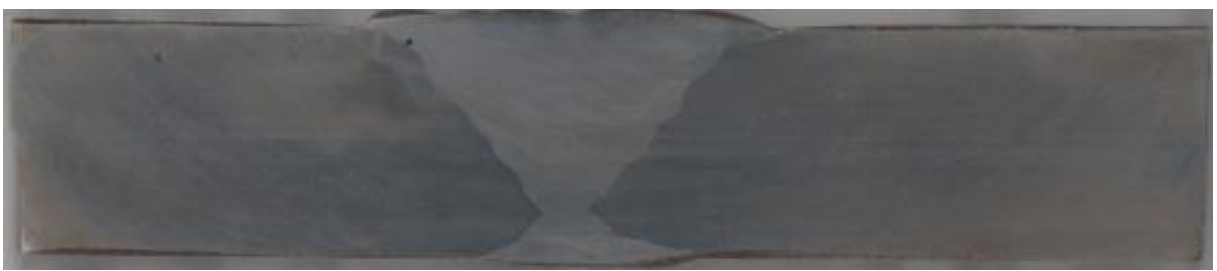

Figura 3: Macrografia da amostra do aço Hardox $450 \mathrm{HB}$. 
Com esta análise, a peça evidenciou a zona termicamente afetada pelo calor (ZTA), o metal de solda e o metal de base, permitindo perceber que a amostra teve uma excelente soldagem, a qual não ocasionou a falta de fusão ou indícios de propagação de trincas, que indicaria a redução de resistência a fadiga do material, apesar da utilização de vários passes para o processo de soldagem. Isto deve-se a fatores como uma adequada velocidade de soldagem, resfriamento e préaquecimento que influenciam diretamente na falta de fusão de uma amostra. A respeito da velocidade de soldagem, pode-se afirmar que se a mesma for muito baixa, ocasionará um aglomerado do metal de solda fundido a frente do arco elétrico, o que implica consequentemente na falta de fusão entre o metal de solda e o metal de base, todavia, Jovanovic et al. (2008) afirma que se a velocidade de soldagem for rápida, o aporte térmico será escasso para fundir este metal de base.

Além disso, pode-se calcular a diluição da amostra, através da Equação 3 que relaciona a área diluída pela área total do metal de adição.

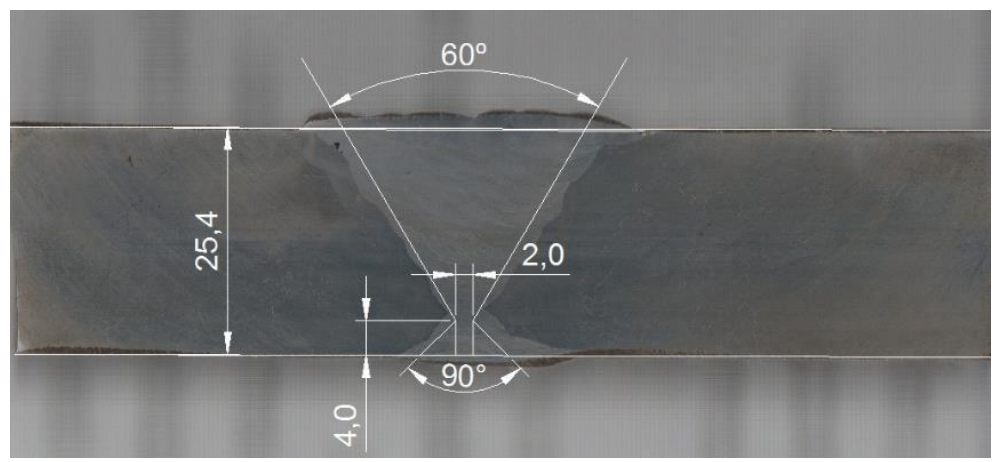

Figura 4: Medidas do corpo de prova para cálculo de diluição.

$$
\text { Diluição }=\frac{\text { Área diluída }}{\text { Área total }}
$$

A área diluída total equivaleu a $98,46 \mathrm{~mm}^{2}$ e a área total foi calculada em $502,33 \mathrm{~mm}^{2}$, logo, a diluição do metal de adição no metal de base foi igual a 19;6\%.

\subsection{MICROGRAFIA}

As figuras 4, 5 e 6 representam a micrografia da amostra do aço Hardox $450 \mathrm{HB}$ em diferentes regiões. 


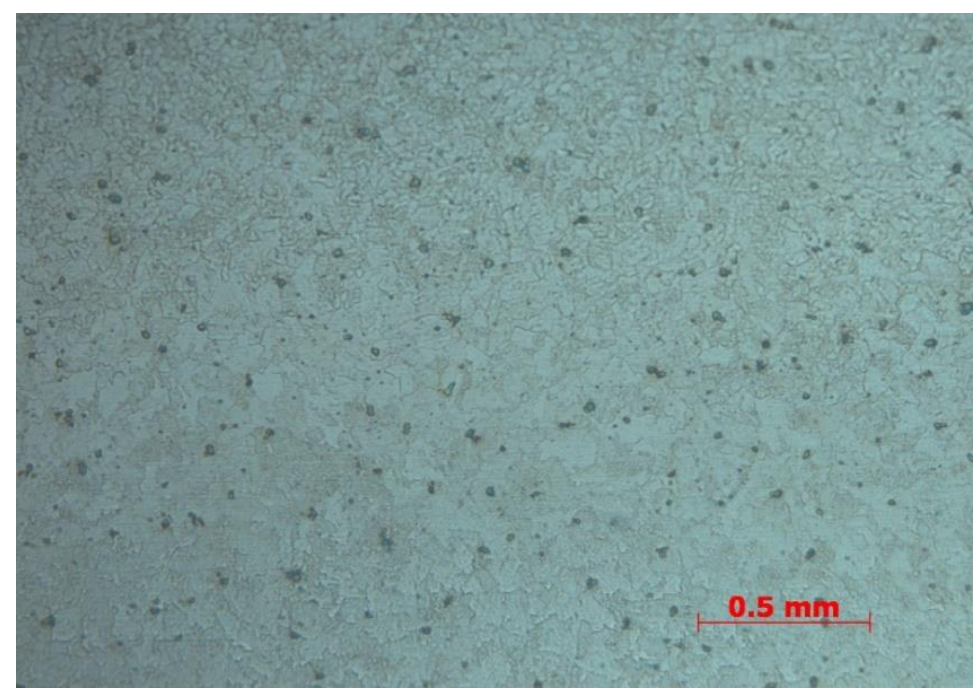

Figura 5: Micrografia da zona termicamente afetada pelo calor (ZTA) com aumento de 400x.

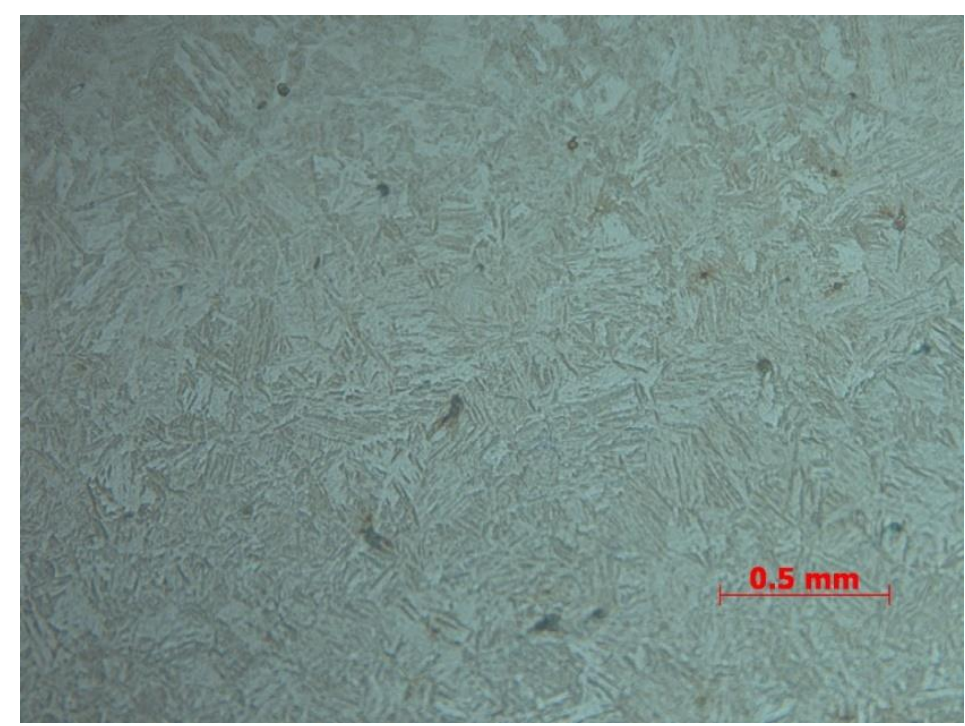

Figura 6: Micrografia do metal de base com aumento de 400x.

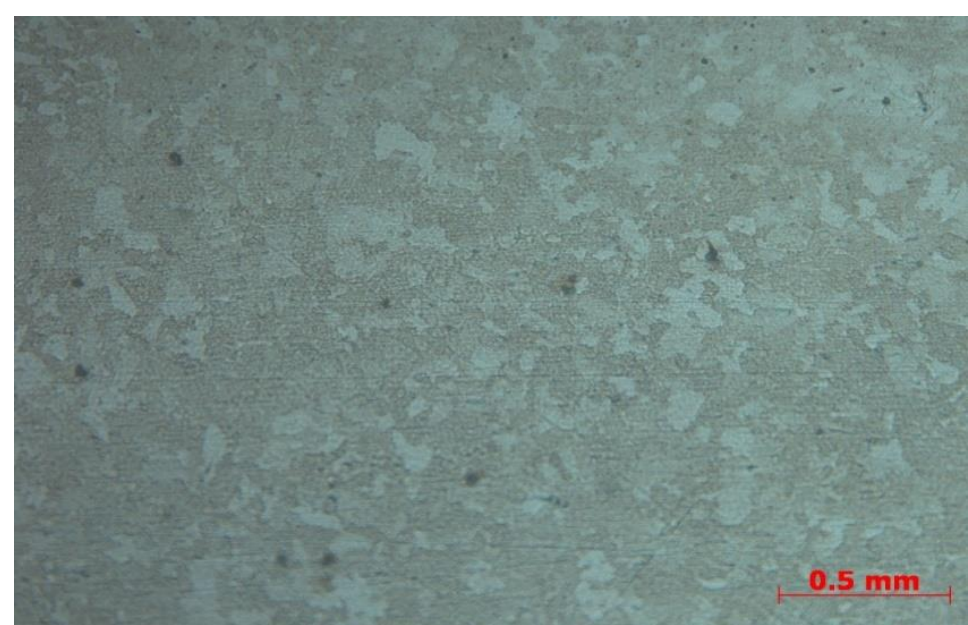

Figura 7: Micrografia do metal de adição com aumento de 400x. 
Em relação a ZTA (figura 5), pode-se observar que a microestrutura se apresenta de forma diferente, o que explica a redução da dureza na região. Pois segundo Silva (2010), os altos picos de temperatura alcançado na região soldada devido à quantidade de passes que vão alterando a microestrutura por conta do aquecimento continuo a cada passe, há o impedimento do crescimento do grão austenítico, originando grãos refinados e a formação de constituintes de menor dureza, como ferrita, perlita e bainita, pois carbonetos nessa região não são facilmente dissolvidos.

Observando a figura 6 obtida no ensaio micrográfico, comprovou-se uma microestrutura martensítica revenida com grãos refinados no metal de base, predominando a presença da martensita com pouca ferrita. Ao analisar a figura 7 , a qual apresenta o metal de adição, a microestrutura assemelha-se a ferrita poligonal, possuindo grande importância por promover uma estrutura altamente tenaz e resistente. Sendo assim, ao realizar uma análise a respeito da dureza, sabendo-se que teoricamente o metal de base possui maior dureza em relação ao metal de adição, pode-se afirmar que através das microestruturas apresentadas que a martensita por possuir grandes quantidades do elemento Carbono é considerada mais dura do que uma microestrutura de ferrita poligonal.

Vale ser ressaltado que os pontos escuros encontrados nas micrografias acima são porosidades, que podem ter sido ocasionadas pela alta corrente, que aumenta a temperatura da poça de fusão, assim elevando a solubilidade da mesma, o que permite a solubilização do elemento Oxigênio e de outros gases, e ao solidificar, esses gases tendem a ir para a superfície permanecendo aprisionados. Outro fator que influencia é o comprimento do arco que permite que quanto maior a distância, maior é facilidade da entrada dos gases.

\subsection{MICRODUREZA}

O gráfico 1 apresenta o perfil de microdureza Vickers analisado em determinados pontos na amostra do aço Hardox $450 \mathrm{HB}$. 


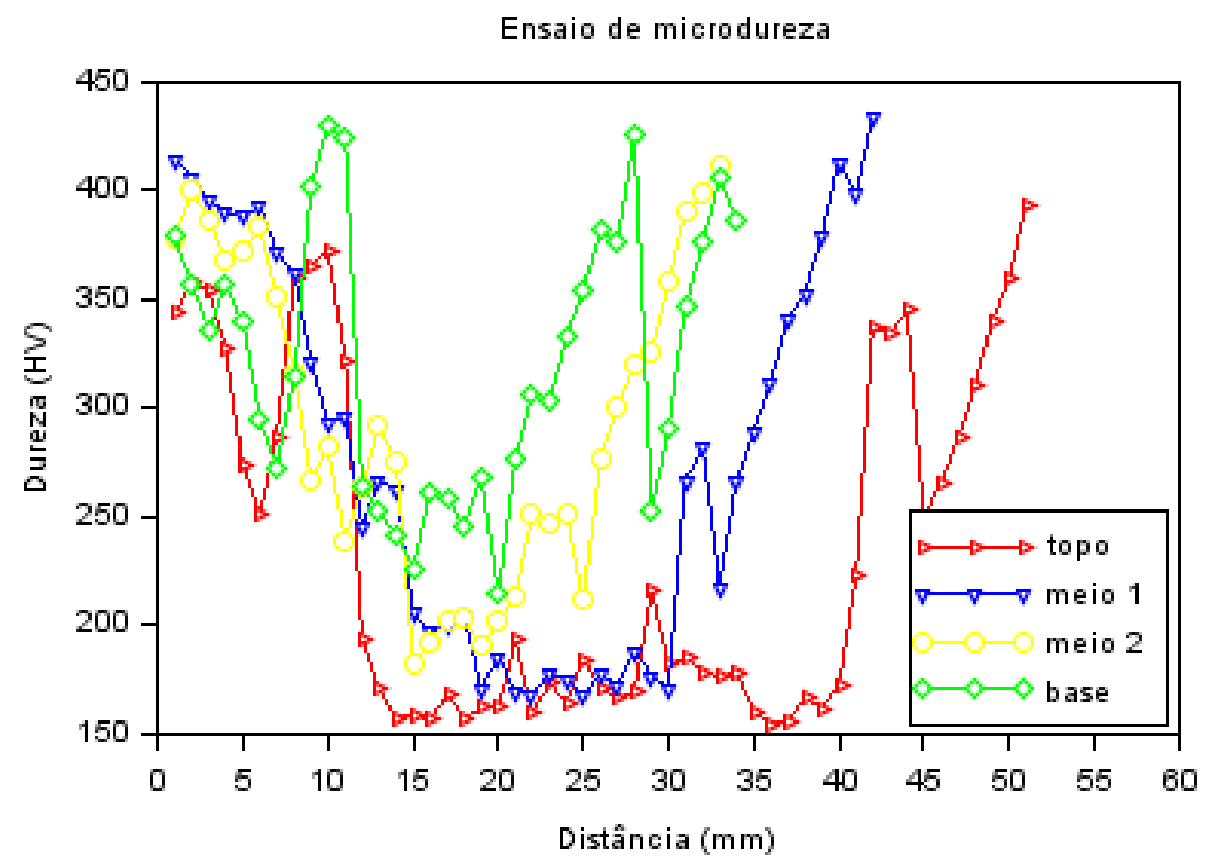

Gráfico 1: Perfil de microdureza.

O metal de base apresentou dureza variando entre 343 a $410 \mathrm{HV}$, possuindo uma redução considerável quando se chegava ao metal de adição, variando entre 150 a $190 \mathrm{HV}$, afinal, isto era esperado, pois, utilizou-se a técnica undermatching para a soldagem, a qual se apropria do metal de adição ter menor resistência que o metal de base, almejando alta tenacidade para diminuir a probabilidade de propagação de trincas.

Em decorrência do refino de grãos no sentindo da ZTA ao metal de solda, pode-se afirmar que isto ocasionou a diminuição da dureza, implicando na presença de microestrutura martensítica na amostra. Sendo assim, a medida que se aproxima do metal de solda a dureza tende a diminuir, pois, segundo Costa (2014) o perfil passa por diversas regiões que apresentam alterações da microestrutura, como por exemplo a região de refino de grãos. A menor resistência a abrasão é determinada por esta baixa dureza, ao se relacionar com o metal de base, visto que este último não sofre influência de temperatura no processo de soldagem.

\section{CONCLUSÃO}

A partir dos ensaios realizados, foi perceptível que os parâmetros de soldagem utilizados na amostra de aço Hardox 450 HB são de extrema importância para que a mesma possa ter alta tenacidade e resistência a dureza, fatores que foram comprovados através da análise da composição química, dos ensaios 
metalográficos e de microdureza. Além disto, percebeu-se que o controle dos elementos de liga influenciará em sua soldabilidade, o que implicará nas escolhas dos parâmetros de soldagem adequados.

Pode-se concluir pela análise química da amostra, ao calcular o carbono equivalente, que a mesma possui média soldabilidade, de acordo com o valor encontrado de aproximadamente 0,62. Além disso, através da macrografia calculouse o valor da diluição da amostra, equivalendo a 19,64, o que implica o quanto o metal de adição dilui-se ao fundir no metal de base, sendo este valor considerável. Como também, pela técnica micrográfica, depreendeu-se que dependendo da região analisada pode se ter presente a microestrutura martensítica ou ferrita poligonal, a qual relaciona-se com as suas propriedades de tenacidade e dureza.

Sabendo que foi utilizado o processo undermatching para soldar esta amostra, o metal de adição deveria ser menos resistente que o metal de base, logo, comprovou-se isto a partir do ensaio de microdureza, o que ajuda a prevenir a não propagação de trincas na peça. Portanto, as técnicas utilizadas foram relevantes para caracterizar esta amostra de aço Hardox $450 \mathrm{HB}$ afim de aprofundar o conhecimento a respeito das suas propriedades para uso posterior.

\section{REFERÊNCIAS}

1 COSTA, V. Análise da tenacidade de uma junta soldada de um aço resistente à abrasão da série 450 HB. 2014. 90 f. Dissertação (Mestrado em Engenharia) Instituto de Engenharia, Universidade Federal do Rio Grande do Sul, Porto Alegre. 2014.

2 VIEGAS, D. Avaliação da resistência ao desgaste de um aço Hardox® 450 submetido a solda de revestimento duro, com arame tubular DIN 8555/MF-10GF-60-GR ultilizando o processo FCAW. 2016. 101 f. Dissertação (Mestrado em Engenharia de Materiais) - Instituto de Engenharia, Centro Federal de Educação Tecnológica de Minas Gerais - CEFET, Belo Horizonte. 2016.

3 SOUZA NETO, F., NOBREGA, U., COELHO, N., RODRIGUES, J., VIANA, H., FARIA, P. Projeto e fabricação de duas vigas de rolagem com perfil soldado "H" em aço Hardox 450. In: CONGRESSO NACIONAL DE SOLDAGEM, 41., 2015, Salvador. Resumos... Salvador, 2015, p.11.

4 JOVANOVIC, M., GRUM, J., URAN, M. Influence of lack of fusion defects on load capacity of MAG welded joints. 17 th World Conference on Nondestructive Testing, Shanghai, p. 25-28, October, 2008.

$5 \mathrm{JUN}, \mathrm{H} . \mathrm{J}$. et al. Effects of deformation and boro non mivrostructure and continuous cooling transformation in low carbono HSLA steels. Materials Science \& Engineering, Elsevier, p. 157-162, 2006.

6 GUIMARÃES, G., SILVA, R., SILVA, L. Soldabilidade de aços resistentes à abrasão da classe de 450 HB de dureza. Consolda, São Paulo, v.16, n. 4, p.360-368, Out/Dez 2011. 